UDC 633.18:631.674.6(574)

LBC 42.112.3(5Ка3)-462

\title{
RICE CULTIVATION TECHNOLOGY AT LOW-PRESSURE DROP IRRIGATION IN THE CONDITIONS OF KYZYLORDA REGION
}

\author{
Gulzinat Temirkhan kyzy Aldambergenova \\ Korkyt Ata Kyzylorda University, Kyzylorda, Kazakhstan \\ Asylkhan A. Shomantaev \\ Korkyt Ata Kyzylorda University, Kyzylorda, Kazakhstan \\ Mustafa Gilman ogly Mustafayev
}

Institute of Soil Science and Agro Chemistry of Azerbaijan National Academy of Sciences, Baku, Azerbaijan

\begin{abstract}
The article explores the method of drip irrigation of agricultural crops, which provides a high coefficient of irrigation water (80-95\%) and land (95\%) use. This method helps to significantly save irrigation water by reducing losses for evaporation and filtration outside the root system zone, which eliminates surface runoff, unevenness of irrigation and creates the ability to maximize the use of irrigated areas for agricultural crops. The use of drip irrigation in vegetable production in the south of Kazakhstan since 2000 has radically changed the approach to the "water - soil - plant" complex. The authors believe that a metered feeding regimen would form a new approach to irrigation of agricultural crops, such as rice. Rice (Oryza sativa L.) as - a food culture serves as one of the products consumed in food. It is grown in 120 countries on the area of more $\overline{\widetilde{\delta}}$ than 165 million hectares. Rice, unlike other agricultural crops, has a high biological plasticity and adaptive ability, which in modern agriculture allows it to be cultivated in a wide range of climatic conditions and irrigation methods, such as flooding, periodic irrigation and dry conditions. In world practice a continuous flooding of checks was the most widespread method of watering. This technology consumes about $50 \%$ of the total volume of irrigation water or $30 \%$ of the world's fresh water reserves. The irrigation rate of rice cultivated * with the use of this technology is in the range of 20-25 thousand $\mathrm{m}^{3} / \mathrm{ha}$, which significantly exceeds the . biological water consumption of rice agrocenosis. A significant part of the irrigation water is lost for filtration, discharges and lateral outflows. Currently, the use of drip irrigation method in rice fields is poorly studied. The research is aimed at substantiating the technology of rice cultivation using a low-pressure drip irrigation method in the conditions of Kyzylorda region.
\end{abstract}

Key words: irrigation technology, rice, irrigation, irrigation rate, productivity.

Citation. Aldambergenova G.T. kyzy, Shomantaev A.A., Mustafayev M.G. ogly. Rice Cultivation Technology at Low-Pressure Drop Irrigation in the Conditions of Kyzylorda Region. Prirodnye sistemy $i$ resursy [Natural Systems and Resources], 2021, vol. 11, no. 3, pp. 49-56. DOI: https://doi.org/10.15688/nsr.jvolsu.2021.3.7 
УДК 633.18:631.674.6(574)

ББК 42.112.3(5Каз)-462

\title{
ТЕХНОЛОГИЯ ВОЗДЕЛЫВАНИЯ РИСА ПРИ НИЗКОНАПОРНОМ КАПЕЛЬНОМ СПОСОБЕ ПОЛИВА В УСЛОВИЯХ КЫЗЫЛОРДИНСКОЙ ОБЛАСТИ
}

\author{
Гулзинат Темирхан кызы Алдамбергенова \\ Кызылординский университет им. Коркыт Ата, г. Кызылорда, Казахстан \\ Асылхан Ашимович Шомантаев \\ Кызылординский университет им. Коркыт Ата, г. Кызылорда, Казахстан \\ Мустафа Гылман оглы Мустафаев \\ Институт почвоведения и агрохимии НАНА, г. Баку, Азербайджан
}

\begin{abstract}
Аннотация. В статье рассматривается капельный способ полива сельскохозяйственных культур, обеспечивающий высокий коэффициент использования оросительной воды (80-95 \%) и высокий коэффициент земельного использования (до 95 \%). При применении данного способа происходит достаточно большая экономия поливной воды в результате снижения ее потерь на испарение и фильтрацию за пределами зоны корневой системы, исключается поверхностный сток, устраняется неравномерность полива и появляется возможность максимально использовать орошаемые площади под сельскохозяйственные культуры. Использование с 2000 г. капельного орошения в овощепроизводстве на юге Казахстана радикально изменило подход к комплексу «вода - почва - растение». По мнению авторов, дозированный режим питания способствовал бы формированию нового подхода в орошении сельскохозяйственных культур, например риса. Рис (Oryza sativa L.) как продовольственная культура является одним из основных продуктов, потребляемых в пищу. Его выращивают в 120 странах на площади более 165 млн га. Рис, в отличие от других сельскохозяйственных культур, обладает высокой биологической пластичностью и адаптационной способностью, что позволяет в современном земледелии возделывать его в широком диапазоне климатических условий и способов полива (например, затопление, периодические поливы, суходольные условия). В мировой практике наибольшее распространение получил такой способ полива, как продолжительное затопление чеков слоем воды. При применении данной технологии расходуется около 50 \% от общего объема оросительной воды, или около 30 \% имеющихся в мире запасов пресной воды. Оросительная норма риса, возделываемого по такой технологии, находится в пределах 23-25 тыс. м³/га, что значительно превосходит биологическое потребление воды рисовым агроценозом. Значительная часть оросительной воды теряется на фильтрацию, сбросы и боковые_оттоки. В настоящее время использование капельного способа полива на рисовых полях недостаточно изучено. Данное исследование направлено на обоснование технологии возделывания риса с применением низконапорной капельной системы полива в условиях Кызылординской области.
\end{abstract}

Ключевые слова: технология орошения, рис, полив, норма орошения, урожайность.

Цитирование. Алдамбергенова Г. Т. кызы, Шомантаев А. А., Мустафаев М. Г. оглы. Технология возделывания риса при низконапорном капельном способе полива в условиях Кызылординской области // Природные системы и ресурсы. - 2021. - Т. 11, № 3. - C. 49-56. - DOI: https://doi.org/10.15688/nsr.jvolsu.2021.3.7

\section{Введение}

Рис (Oryza sativa L.) является одним из основных продовольственных продуктов. В 120 странах мира рис выращивают на площади более 165 млн га. В отличие от других продовольственных сельскохозяйственных культур рис обладает высокой биологической пластичностью и адаптационной способ- ностью, что позволяет возделывать его в широком диапазоне климатических условий. В мировой практике наибольшее распространениеполучил такой способов полива, как продолжительное затопление чеков слоем воды. При таком способе полива расходуется 50 \% от общего объема оросительной воды, что составляет около $30 \%$ мирового запаса пресной воды. При такой технологии ороситель- 
ная норма риса находится в пределах 2325 тыс. ${ }^{3} /$ га. Естественно, большая часть оросительной воды теряется на фильтрацию, сбросы и боковые оттоки.

Многие страны, в том числе Казахстан, испытывают острый дефицит водных ресурсов, определенное ограничение забора поливной воды. В связи с глобальным изменением климата, приростом населения, нарушением экологических ограничений природопользования дефицит пресной воды и продовольствия обостряется до критических значений. Поэтому традиционная технология орошения продолжительным затоплением будет испытывать нехватку оросительной воды. Следовательно, поиск путей по снижению затрат поливной воды для орошения риса имеет большое экономическое, социальное и экологическое значение.

В качестве сортов риса для проведения опыта выбраны «Сыр Сулуы» и «Ай Керим», которые вывели ученые в ТОО «КазНИИ рисоводства им. И. Жахаева» - А.Н. Подольских, С.М. Байбосынова, Б.К. Абилханова, Р.М. Алтынбаева и С.М. Умирзаков [5; 6].

Сорт «Сыр Сулуы» выведен методом индивидуального отбора из гибридной популяции сложного скрещивания 6 Амс/Кулон//Оскар// Маржан и относится к разновидности субвульгарис (SubvulgarisKan). Высота растения - 95$100 \mathrm{~cm}$, с длиной метелки 18-21 см, плотная, среднеразвесистая, несет около 90-110 колосков. Урожайность - 70-80 ц/га.

Сорт «Ай Керим» - среднеспелый, высокоурожайный (80-85 ц/га), солеустойчивый, создан методом индивидуального отбора из сорта «Маржан», с вегетационным периодом 110-115 дней. Высота растений - 115-125 см, с прочным стеблем средней толщины, устойчивый к полеганию. Длина метелки - 2325 см, наклонная, слаборазвесистая, с плотностью колосков 6-7 шт./см. Общее количество колосков в метелке - 150-170 штук.

\section{Объект исследование и методика}

В последние годы в мировой практике для снижения оросительных норм риса активно проводятся исследования по возделыванию аэробного риса. Данная технология дает возможность возделывать рис в ненасыщенной водой почве с поддержанием влажности корнеобитаемого слоя почвы от 70 до $100 \%$ HВ в течение всего жизненного цикла растений $[1 ; 2 ; 4]$.

Однако такая технология орошения аэробного риса базируется на использовании полива по бороздам, полосам, дождеванием. Этим способам полива свойственны существенные недостатки, связанные с потерями воды на фильтрацию и испарение, поэтому наши полевые исследования направлены на водосберегающую технологию с использованием капельного способа полива риса.

Кызылординская область расположена на юге Казахстана, вдоль нижнего течения p. Сырдарьи. Климат региона резко континентальный: лето - жаркое, зима - холодная с неустойчивым снежным покровом. В холодный период года над низовьями р. Сырдарьи возникает малоподвижный циклон, вызывающий холодную погоду с длительными осадками.

Климат очень засушливый, в ноябре марте выпадает до 152-159 мм, а в апреле октябре - 129-144 мм осадков в год. Сумма положительных температур воздуха выше $10{ }^{\circ} \mathrm{C}$ достигает $3800-4600{ }^{\circ} \mathrm{C}$.

Почвенно-растительный покров области относится к зоне пустынь и характеризуется значительным разнообразием, подразделяясь на два больших района: увлажненные (гидроморфные) - это почвы земледельческой полосы; иссушенные (субаэральные), местами имеющие следы древнего орошения, - это пустынная часть.

Несмотря на разнообразие, все равнинные почвы обладают некоторыми общими признаками, имеющими агрономическое значение. Луговые и лугово-болотные почвы содержат значительное количество перегноя и обладают более высокими запасами питательных веществ. Содержание гумуса достигает $4 \%$, чаще - $1,5-30 \%$, поверхностно засолены - 1,5-2,5 \%, степень засоления - хлоридно-сульфатная. Грунтовые воды залегают на глубине 2-3 м, пресные и солоноватые. Почвы пригодны под рис и другие сельскохозяйственные культуры [3; 6].

Единственным источником орошения в Кызылординской области является р. Сырдарья - вторая по водности река в Средней Азии, протекающая через территории 4 су- 


\section{НОВЫЕ БИОТЕХНОЛОГИИ В АГРОПРОМЫШЛЕННОМ КОМПЛЕКСЕ}

веренных государств в Центральной Азии: Киргизия, Таджикистан, Узбекистан и Казахстан. Учитывая дефицит поливной воды в низовье р. Сырдарьи, сельхозпроизводители региона все чаще стали применять водосберегающую технологию полива сельскохозяйственных культур - систему капельного орошения. При капельном орошении увлажнение почвы просходит только в зоне распространения корней и вместе с оросительной водой подаются удобрения.

Опытно-экспериментальные исследования по применению низконапорной капельной системы орошения риса проводились в частном секторе расположенного в близи опытного хозяйства Казахского научно-исследовательского института рисоводства (КазНИИ рисоводства) им. И. Жахаева в поселке Караултобе в 7 км от г. Кызылорда. Схема опытного участка площадью $343 \mathrm{~m}^{2}$ и технические средства представлены на рисунке 1 .

Была использована пластиновая емкость «ЕВРОКУБ» на 1000 м, снаружи имеющая металлическую обрешетку и заливную горловину диаметром 20 см, снизу сливное отверстие с краном, также имеется дыхательный клапан для сброса давления. Низ- конапорная капельная система включает: водосчетчик крыльчатый «I'mPulsu Plus» для измерения объема воды, попадающей в капельную систему, монометр типа МР-3-И (№ 11032183) для измерения давления воды в системе, пластиновый трубопровод диаметром 50 мм для доставки оросительной воды от напорного бака к капельным лентам, воздушный клапан, предназначенный для выпуска и пуска воздуха в систему, капельная лента с расстоянием между капельницами 70 см. Конструкция капельницы показана на рисунке 2.

Для системы низконапорного капельного орошения необходимо учитывать требования к качеству оросительной воды и почвенно-климатические условия зоны орошения. Не допускается поливать водой, эпидемиологические и паразитологические показатели которой превышают санитарные нормы и которая, следовательно, является вредной для человека и животных. Допускается поливать водой с общей минерализацией от 0,5 до 1,0 г/л. Допустимые значения минерализации оросительной воды должны быть увязаны с величиной индекса сухости $\left(\mathrm{K}_{6}\right)$ по М.И. Будыко:

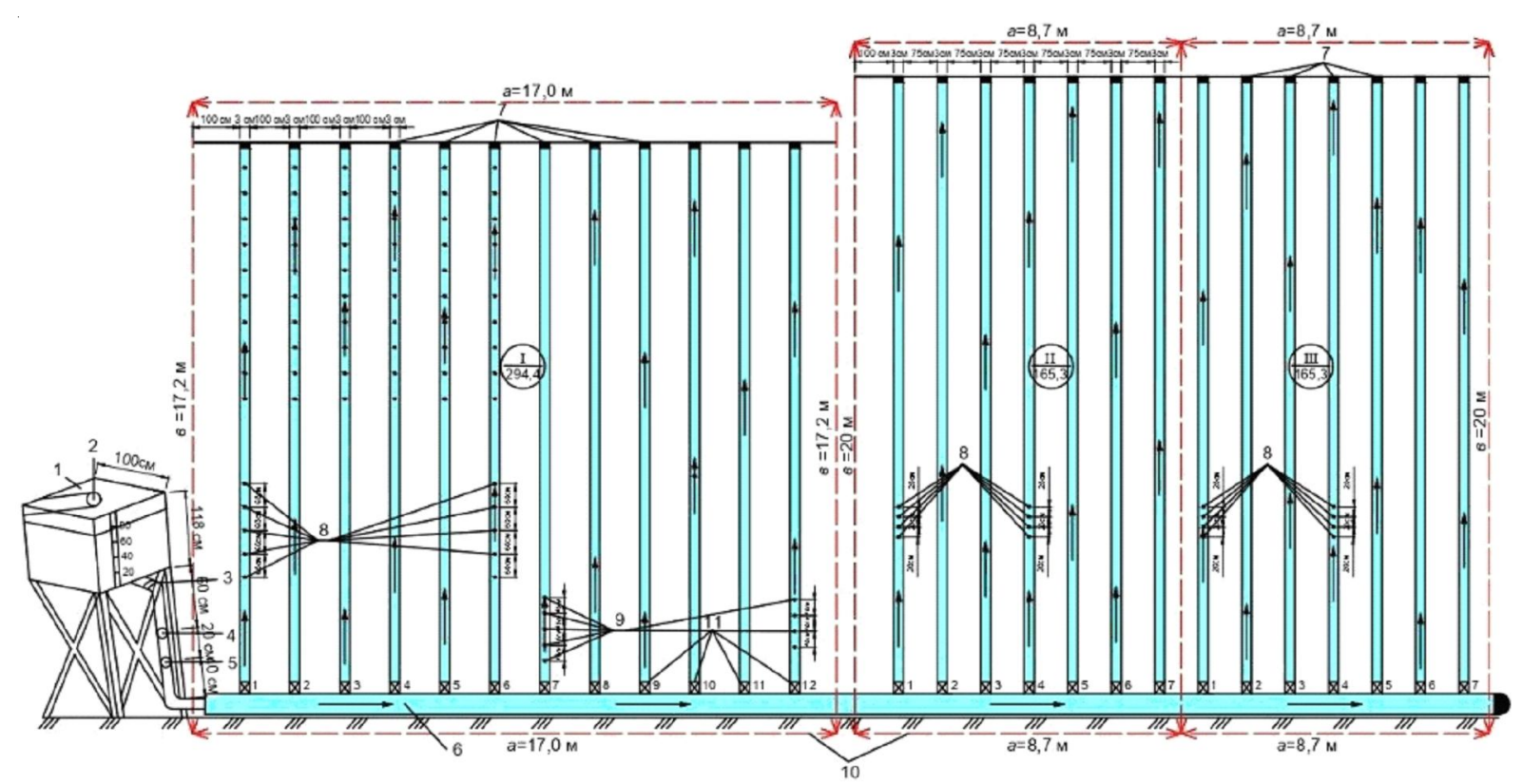

Рис. 1. Схема опытного участка низконапорной капельной системы:

1 - кран подводящего трубопровода; 2 - напорный бак емкостью 1000 м; 3 - кран для выпуска воды в капельную систему; 4 - монометр для измерения воды; 5 - водосчетчик для измерения расхода воды в системе; 6 - магистральный трубопровод воды; 7 - капельные ленты; 8 - капельницы, расположенные на расстоянии 70 см; 9 - кран для выпуска воды в капельную ленту 


$$
\mathrm{K}_{6} \frac{\sum R}{L \cdot Q_{c}}
$$

где $\sum R$ - сумма рационального баланса за год,

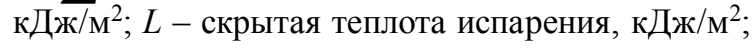
$Q_{c}-$ количество осадков за год, мм.

\section{Результаты и обсуждение}

Опытно-экспериментальные исследования проводились на среднесуглинистых почвах. На глубине от 0 до 60 см почвы очень сильнозасоленные сульфатно-хлоридным засолением. Далее от 60 до 100 см почва была среднезасоленной сульфатным засолением. Почва опытного участка отличается очень низким плодородием: содержание гумуса 0,28-0,43 \%; азота - 5,6-43,4 мг/кг; массовая доля фосфора - 24,8-32,4 мг/кг; калия - 116226 мг/кг; $\mathrm{pH}=6,5-5,8$.

Экспериментальным путем был определен расход одной капельницы в 3-кратной повторности при различных давлениях воды. При давлении воды $P=18$ кПа расход одной капельницы составил $Q=15$ мг/мин, или 0,015 л/мин. На одной капельной ленте 67 шт. капельниц, на опытном участке расмещены 14 капельных лент. Следовательно, расход на участке площадью 348 м $^{2}$ будет равен 14,1 л/мин, или $846 \pi / \mathrm{u} \approx 0,846 \mathrm{~m}^{3} / \mathrm{ч}$.

Для получения детальных метеоданных использовали устройство метеонаблюдений «Weather Bucket» (производитель - Япония), установленное на опытных станциях КазНИИ рисоводства им. И. Жахаева.

Система обработки почвы в рисовых севооборотах складывается из 2 этапов - основного и предпосевного.

Цель основной обработки - создание оптимального температурного и пищевого режима почвы для посева и прорастания семян, развития растений и уничтожения сорной растительности. Здесь происходит окисление вредных соединений, почва обогащается кислородом, повышается микробиологическая активность и мобилизация питательных веществ, разрушаются капиллярные поры в почвах, задерживается поднятие токсичных солей в корнеобитаемую зону почвы [7;8].

В нашем случае была проведена предпосевная обработка почвы.

Для вспашки был использован плуг типа ПЛН 4-35, навешенный в агрегате с трактором К-701. Почва была вспахана на глубину 25-27 см. С помощью этого способа была достигнута хорошая разделка почвы, произведено измельчение глыб и комков, придание почве необходимого агрегатного состояния, аэрация и пропашка пахотного слоя.

Проблема получения оптимально густых всходов риса в условиях засоленных почв в низовье р. Сырдарьи не решена до настоящего времени. Результаты исследований свидетельствуют о тесной взаимосвязи полевой всхожести семян с густотой роста растений и зерновой продуктивностью риса.

Способы посева также влияют на уражайность риса. При узкорядном и перекрестном способах посева на $1 \mathrm{~m}^{2}$ насчитывалось от 260 до 380 шт. всходов и к уборке сохраня-

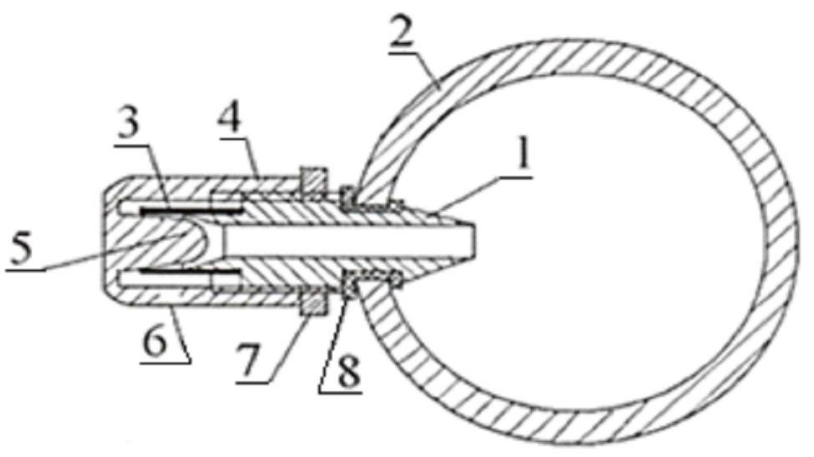

Рис. 2. Конструкция капельницы:

1 - щтуцер; 2 - поливной трубопровод диаметром 50 мм; 3 - упругая резиновая трубка; 4 - крышка щтуцера; 5 - консольный выступ; 6 - отверстия на крышке; 7 - контргайка; 8 - прокладка 


\section{НОВЫЕ БИОТЕХНОЛОГИИ В АГРОПРОМЫШЛЕННОМ КОМПЛЕКСЕ}

лось 220-300 шт. растений, а после уборки 90-120 шт. (на $50 \%$ меньше) [1].

В нашем случае расстояние в узкорядном посеве было 7-7,5 см и высевали вручную. Поливные опыты выполняли согласно требованиям методик опытного дела.

Сорта «Сыр Сулуы» и «Ай Керим» высевали 5-6 июня и первый полив произвели 7 июня 2020 года. Получение равномерных и полных всходов риса является очень важной задачей в технологии его возделывания, так как зерна риса находятся в цветковых пленках, эндосперм плотный и роговидный, масса 1000 шт. зерн весит от 25 до 40 г, пленчатость $-18-25 \%$. Семена риса для прорастания впитывают 23-28 \% воды от массы семян, в этот период они не нуждаются в кислороде, эндосперм развивается за счет анаэробного дыхания.

При глубокой заделке семян на 4-5 cм анаэробное дыхание усиливается и семена риса гибнут. Поэтому семена риса закладывали на глубину 2-3 см. При температуре ниже $10{ }^{\circ} \mathrm{C}$ зародыши семян загнивают, оптимальной температурой прорастания семян считается $34{ }^{\circ} \mathrm{C}$. В зависимости от температуры воздуха, влажности почвы, энергии семян, от прорастания до появления всходов проходит 7-15 дней. Семена риса «Сыр Сулуы» и «Ай Керим» проросли за 7 дней, и в фазу всходов образовалось до 4 листьев длиной от 7 до 13 см (это этап дифференциации и формирования листьев и начало фазы кущения, которое проходит в аэробных условиях (рис. 3).

В период всходов происходит быстрый рост корневой системы и появляются воздушные ходы (клетки), которые обеспечивают растение кислородом. Малое количество корневых волосков обусловливает очень низкую сосущую силу корней, поэтому всасывание происходит по всей поверхности.

В связи с низким содержанием воды в тканях риса требуется его регулярный и обильный полив. Учеными установлено, что на единицу сухого вещества риса необходимо в 82 раза меньше воды, чем пщенице. Вода растениям нужна для оптимального роста и развития, она поступает из почвы. Влага для растительного организма является необходимым условием жизни. Выращиваемые зерновые культуры могут нормально развиваться при нижнем предполивном пороге влажности почвы 60-65 \% НВ. Рис при такой низкой предполивной влажности почвы может начать снижение нарастания растительной массы. Снижение содержания влаги в корнеобитаемом слое почвы, когда растения не могут получать влагу в полном обьеме, приводит к нарушению водного баланса

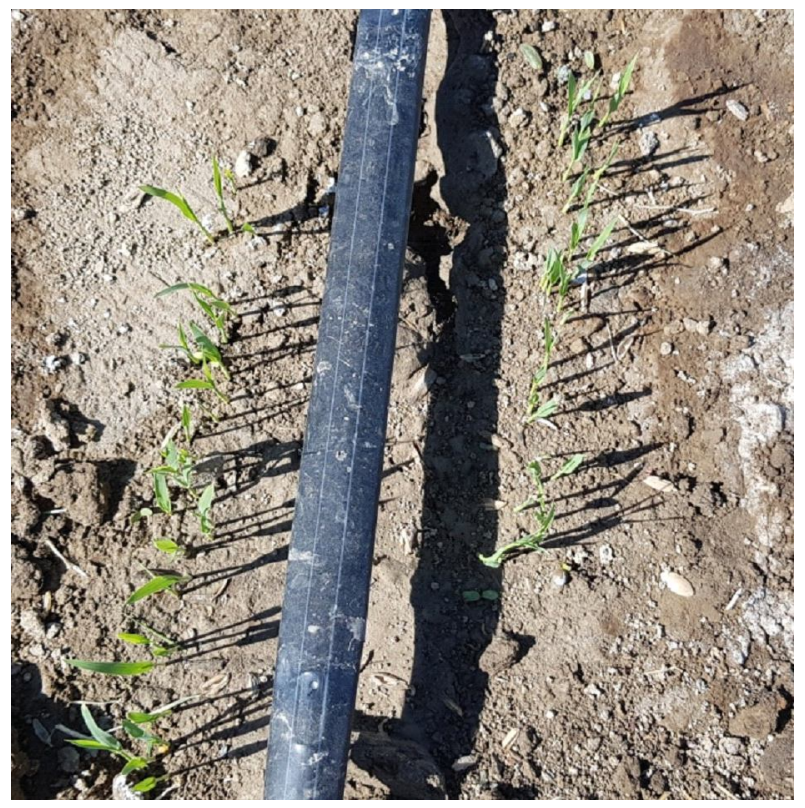

Рис. 3. Прорастание семян риса и появление всходов 
в растительном организме, и возникают признаки завядания риса.

Исходя из этого, многие ученые считают, что при выращивании аэробного риса нужно поддерживать водный режим не ниже 80 \% НВ, при этом улучшается водно-воздушный режим почвы, что благоприятно сказывается на жизнедеятельности риса [8].

Водный режим почвенного слоя до $60 \mathrm{~cm}$ регулировали по предполивному порогу влажности по следующей схеме: 1) от посева до начала сушки поддерживали предполивной порог влажности до 70 \% HB; 2) от сущения до конца молочной спелости -80 \% НB; 3 ) от конца молочной до полной спелости зерна $-70 \%$ НВ. Норма полива при 70 \% НВ составила от 19,14 до 20,0 м³ на 348 м $^{2}$ опытного участка; при $80 \%$ НВ - от 12,0 до $13 \mathrm{~m}^{3}$. При переводе на 1 га при $70 \%$ НВ будет 546-575 м³ га; при $80 \%$ НВ - 345$373,6 \mathrm{~m}^{3} /$ га.

Для поддержания дифференцированного водного режима почвы по регламенту 70-8070 \% за вегетационный период повели 3 полива нормой 575 м $^{3} /$ га и 12 поливов по 373,6 м³ $^{3}$ га (4483 м³ год).

2020 г. для Кызылординской области был среднесухим, оросительная норма риса составила $6208 \mathrm{~m}^{3} /$ га.

На засоленных землях нашего региона при постоянном затоплении оросительная норма риса составляет 2435 м³/га, объем сбросного стока равен 1000 м$^{3} /$ га $[5 ; 7 ; 8]$.

\section{Выводы}

Таким образом, наши опыты по возделыванию риса с использованием низконапорной капельной системы орошения обеспечивали гибкое регулирование запасов влаги в корнеобитаемом слое почвы с поддержанием температуры воздуха и влажности в приземном слое воздуха в благоприятных для растений пределах.

Данная технология может быть применима в каждой природно-хозяйственной зоне нашего региона и позволяет обеспечивать возможность регулирования микроклимата орошаемого поля в соответствии с фазами роста и развития растений и их биологическими особенностями.
Как показывают опыты зарубежных ученых, применение капельного орошения при возделывании риса обеспечивает получение планируемой урожайности при снижении затрат оросительной воды на единицу площади в 3-5 раз по сравнению с традиционной технологией орошения, что в то же время позволит избежать экологические проблемы, связанные с продолжительным поддержанием слоя воды в чеках и способствует получению высокой урожайности.

\section{СПИСОК ЛИТЕРАТУРЫ}

1. Гричаная, Т. С. Применение капельного орошения при возделывании овощных культур на юге Казахстана / Т. С. Гричаная, Д. А. Першуков // Мелиорация и водное хозяйство: проблемы и пути решения. В 2 т. Т. 1 : материалы Междунар.-практ. конф. - М. : ВНИИА, 2016. - С. 180-184. - (Костяковские чтения).

2. Олжабаева, А. О. Влияние постоянного слоя затопления на водно-солевой режим почвы и урожай риса / А. О. Олжабаева, Ж. Н. Байманов // Известия Национальной академии наук Республики Казахстан. Серия аграрных наук. - 2016. - № 6. C. $104-108$.

3. Система сельскохозяйственного производства Кызылординской области : рекомендации. Алматы : Бастау, 2002. -512 c.

4. Современные перспективные водосберегающие способы полива в Нижнем Поволжье / М. С. Григоров [и др.]. - Волгоград : Нива, 2010. $-240 \mathrm{c}$.

5. Технология капельного полива риса в условиях Кызылординской области / С. И. Умирзаков [и др.] // Известия Национальной академии наук Республики Казахстан. Серия аграрных наук. - 2017. № 6. - С. 154-162.

6. Умирзаков, С. И. Рисовые оросительные системы Кызылординской области: современное состояние и перспективы их развития / С. И. Умирзаков, Ж. Н. Байманов. - Кызылорда : Атамекен, 2017.

7. Effect of Irrigation and Fertilizers on Rice Yield in Conditions of Kyzylorda Irrigation Array /A. O. Olzhabayeva [et al.] // Biosciences Biotechnology Research Asia. - 2016. - Vol. 13, № 4. - P. 2045-2053. DOI: http://dx.doi.org/10.13005/bbra/2363.

8. Technology and Regime of Sugar Beet Drip Irrigation with Plastic Mulching Under the Conditions of the Jambyl Region / K. Massatbayer [et al.] // Irrigation and Drainage. - 2016. - Vol. 65, № 5.1. P. 7620-7630. - DOI: https://doi.org/10.1002/ird.2084. 


\section{REFERENCES}

1. Grichanaya T.S., Pershukov D.A. Primenenie kapel'nogo orosheniya pri vozdelyvanii ovoshchnykh kul'tur na yuge Kazakhstana [The Use of Drip Irrigation in the Cultivation of Vegetable Crops in the South of Kazakhstan]. Melioratsiya $i$ vodnoe khozyaystvo: problemy i puti resheniya. V 2 t. T. 1: materialy Mezhdunar.-prakt. konf. [Melioration and Water Management: Problems and Solutions. In 2 Vols. Vol. 1. Proceedings of the International Practical Conference]. Moscow, VNIIA, 2016, pp. 180-184. (Kostyakovskie chteniya [Kostyakov Readings]).

2. Olzhabayeva A.O., Baymanov Zh.N. Vliyanie postoyannogo sloya zatopleniya na vodno-solevoy rezhim pochvyi urozhay risa [Effect of Permanent Bed Flooding of Water and Salt Regime of the Soil and Crop Rice]. Izvestiya Natsional'noy akademii nauk Respubliki Kazakhstan. Seriya agrarnykh nauk, 2016, no. 6, pp. 104-108.

3. Sistema sel'skokhozyaystvennogo proizvodstva Kyzylordinskoy oblasti: rekomendatsii [The System of Agricultural Production of Kyzylorda Region. Recommendations]. Almaty, Bastau Publ., 2002. 512 p.

4. Grigorov M.S. et al. Sovremennye perspektivnye vodosberegayushchie sposoby poliva $v$ Nizhnem Povolzhye [Modern Promising Water-
Saving Irrigation Methods in the Lower Volga Region]. Volgograd, Niva Publ., 2010. 240 p.

5. Umirzakov S.I., Baymanov Zh.N., Olzhabayeva A.O. et al. Tekhnologiya kapel'nogo poliva risa $\mathrm{v}$ usloviyakh Kyzylordinskoy oblasti [Technology of Drip Irrigation of Rice in the Conditions of the Kyzylorda Region]. Izvestiya Natsional'noy akademii nauk Respubliki Kazakhstan. Seriya agrarnykh nauk, 2017, no. 6, pp. 154-162.

6. Umirzakov S.I., Baymanov Zh.N. Risovye orositel'nye sistemy Kyzylordinskoy oblasti: sovremennoe sostoyanie i perspektivy ikh razvitiya [Rice Irrigation Systems of Kyzylorda Region: Modern State and Perspectives for Its Development]. Kyzylorda, Atameken Publ., 2017.

7. Olzhabayeva A.O., Rau A.G., Sarkinov Ye.S. et al. Effect of Irrigation and Fertilizers on Rice Yield in Conditions of Kyzylorda Irrigation Array. Biosciences Biotechnology Research Asia, 2016, vol. 13, no. 4, pp. 2045-2053. DOI: http://dx.doi.org/ $10.13005 / \mathrm{bbra} / 2363$.

8. Massatbayer K., Dzhzbasov N., Nurabayev D. et al. Technology and Regime of Sugar Beet Drip Irrigation with Plastic Mulching Under the Conditions of the Jambyl Region. Irrigation and Drainage, 2016, vol. 65, no. 5.1, pp. 7620-7630. DOI: https://doi.org/10.1002/ird.2084.

\section{Information About the Authors}

Gulzinat Temirkhan kyzy Aldambergenova, Doctoral Student, Department of the Water Management and Land Management, Korkyt Ata Kyzylorda University, Aiteke bi St, 29a, 120014 Kyzylorda, Kazakhstan, gulzi_31@mail.ru

Asylkhan A. Shomantaev, Doctor of Sciences (Agriculture), Professor, Department of the Water Management and Land Management, Korkyt Ata Kyzylorda University, Aiteke bi St, 29a, 120014 Kyzylorda, Kazakhstan, shomantayev53@gmail.com

Mustafa Gilman ogly Mustafayev, Doctor of Sciences (Agriculture), Academician of the Russian Academy of Natural History, Head of the Laboratory of Soils Melioration, Institute of Soil Science and Agro Chemistry of Azerbaijan National Academy of Sciences, M. Ragima St, 5, AZ10073 Baku, Azerbaijan, meliorasiya58@mail.ru

\section{Информация об авторах}

Гулзинат Темирхан кызы Алдамбергенова, докторант кафедры водного хозяйства и землеустройства, Кызылординский университет им. Коркыт Ата, ул. Айтеке би, 29a, 120014 г. Кызылорда, Казахстан, gulzi_31@mail.ru

Асылхан Ашимович Шомантаев, доктор сельскохозяйственных наук, профессор кафедры водного хозяйства и землеустройства, Кызылординский университет им. Коркыт Ата, ул. Айтеке би, 29a, 120014 г. Кызылорда, Казахстан, shomantayev53@gmail.com

Мустафа Гылман оглы Мустафаев, доктор сельскохозяйственных наук, академик Российской академии естествознания, заведующий лабораторией мелиорации почв, Институт почвоведения и агрохимии НАНА, ул. М. Рагима, 5, AZ10073 г. Баку, Азербайджан, meliorasiya58@mail.ru 